DOI: $10.5216 /$ racs.v4.57997

\title{
Interculturalidad en la cotidianidad de las comunidades originarias de región norte selva de Chiapas
}

Manuel Lopéz López ${ }^{1}$

\section{RESUMEN}

Este artículo parte de la discusión sobre el discurso de las políticas interculturales en el estado mexicano, así como las condiciones que enfrentan las familias originarias de la region norte selva del estado de Chiapas, con el fin de comprender y explicar los mecanismos y procesos de educación intercultural que emplea la familia originaria para garantizar su hacer en la cotidianidad. Al hablar de educación familiar necesariamente se hace hincapié en los procesos de enculturación, endoculturación y socialización ya que son éstos los que posibilitan la permanencia o el cambio de los patrones propios de la cultura. Las comunidades de la región se constituye como una unidad en la que todos contribuyen en la medida de sus posibilidades; por lo que, la aspiración de un mejoramiento en sus condiciones de vida permite los cambios en su estructura y organización familiar al buscar nuevas formas y fuentes de subsistencia que sean más beneficiosas y menos sufridas que el campo.

PALABRAS CLAVE: Educación Intercultural. Cotidianidad. Socialización. Escuela.

\section{Interculturalidade no cotidiano das comunidades originárias da selva norte de Chiapas}

\section{RESUMO}

Este artigo é parte da discussão sobre o discurso das políticas interculturais no estado mexicano, bem como as condições enfrentadas pelas famílias originais da região de selva norte do estado de Chiapas, a fim de compreender e explicar os mecanismos e processos de educação intercultural que a família original usa para garantir o seu fazer na vida diária. Quando se fala em educação familiar, coloca-se ênfase nos processos de enculturação, endoculturação e socialização, uma vez que são estes que possibilitam a permanência ou a mudança dos próprios padrões da cultura. As comunidades da região são constituídas como uma unidade na qual todas contribuem para o alcance de suas possibilidades; portanto, a aspiração de uma melhoria em suas condições de vida

\footnotetext{
${ }^{1}$ Doutor e mestre em Pedagogia pela Unión de Maestros e la Nueva Educación para México (UNAM). Professor vinculado a Secretaria de Educação Pública. Técnico Pedagógico das Escolas Normais Bilíngues do Estado de Chiapas. San Cristóbal de las Casas, Estado de Chiapa, México. E-mail: witomx @ yahoo.vom.mx.
} 
permite mudanças em sua estrutura familiar e organização ao buscar novas formas e fontes de subsistência que sejam mais benéficas e menos sofridas que o campo.

PALAVRAS-CHAVE: Educação Intercultural. Cotidianidade. Socialização. Escola.

\title{
Interculturality in daily life of communities originating in the northern jungle of Chiapas
}

\begin{abstract}
This article is part of the discussion about the discourse of intercultural policies in Mexico, besides the conditions faced by the original families of the northern jungle region of the state of Chiapas, in order to understand and explain the mechanisms and processes of intercultural education that the original family uses to keep up with their daily affairs. When it comes to family education, emphasis is placed on processes of enculturation, endoculturation and socialization, once they are the ones who grant the permanence or change of the culture's own patterns. The local communities gather as a unit in which everyone takes part in the achievement of their possibilities; therefore, the eagerness of an improvement in their living conditions allows changes in their family structure and organization as they aim for new forms and sources of subsistence that are more beneficial and less struggle than the countryside.
\end{abstract}

KEYWORDS: Intercultural Education. Daily Life. Socialization. School.

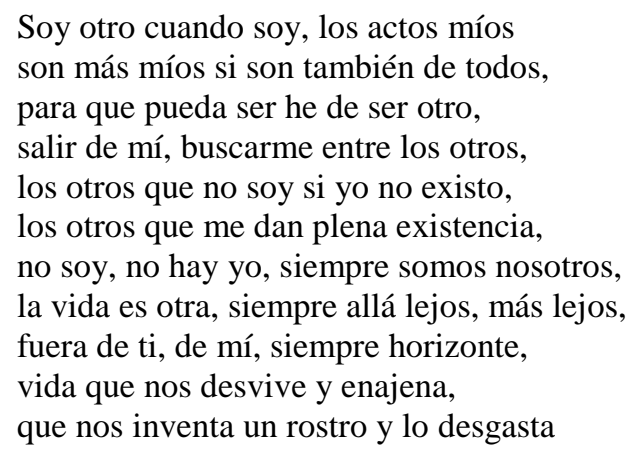

Octavio Paz

\section{La educación intercultural bilingüe en el contexto mexicano}

La educación indígena intercultural bilingüe es una de las "principales finalidades" de la $\mathrm{SEP}^{2}$, con la creación de la Coordinación General de Educación Intercultural y Bilingüe (CGEIB)

2 Por acuerdo del Ejecutivo Federal, el 22 de enero de 2001 se creó la Coordinación General de Educación
Intercultural Bilingüe (CGEIB) de la Secretaría de Educación Pública. A la letra dice "Que nuestro país reconoce y
valora la diversidad étnica, cultural y lingüística como uno de los pilares fundamentales en que habrá de fincar y
construir la identidad de un Estado-Nación multicultural, democrático, equitativo y soberano; Que a pesar del R. Articul.const.saber, 2019, v.4: e57997 
con la misión "Contribuir a la construcción de una sociedad más justa y equitativa, mejorando y ampliando las oportunidades educativas de la población indígena y promoviendo relaciones más igualitarias y respetuosas entre los integrantes de toda la sociedad mexicana" (CGEIB, 2011) aunado la consolidación y promoción de la política intercultural ${ }^{3}$ bilingüe en coordinación con las instancias competentes. Así como la formulación y evaluación de programas de educación intercultural bilingüe con la finalidad de formar a los nuevos ciudadanos en un espacio de convivencia en condiciones igualitarias, mediante el desarrollo de "modelos curriculares" que atiendan la diversidad, el desarrollo y difusión de las lenguas indígenas, así como la producción de materiales en lenguas indígenas.

La educación indígena le corresponde por mandato constitucional aplicar sistemáticamente tareas específicas propias del plan y programas y reformas que de ellas deriven "Las autoridades educativas locales, previa consulta al Consejo Estatal Técnico de Educación correspondiente, propondrán para consideración y, en su caso, autorización de la Secretaría, contenidos regionales que -sin mengua del carácter nacional de los planes y programas citadospermitan que los educandos adquieran un mejor conocimiento de la historia, la geografía, las

impulso cuantitativo que se ha dado a la educación en las áreas indígenas en las últimas tres décadas, la calidad con equidad y pertinencia, sigue siendo un problema fundamental; Que existe gran riqueza potencial y creativa contenida en el carácter pluricultural y multilingüe de la nación mexicana, por lo que es necesario crear una instancia que garantice que en la prestación de los servicios educativos se reconozca la diversidad étnica, lingüística y cultural de la Nación, y que el momento histórico que vive el país es de suma trascendencia para que la política educativa nacional asuma el compromiso de impulsar la construcción del rostro plural del México moderno de cara al siglo XXI" (Diario Oficial, 2001).

${ }^{3}$ Los orígenes de la interculturalidad surgen de diversas maneras en los contextos sociales: en Europa por las condiciones de migración entendidas por atención a estos como una forma de atención a la diversidad interculturalmente con una política cultural del grupo dominante (los migrantes no pertenecen a la nación, aun que vivan por años), así mismo en USA es el resultado de una lucha constante de los derechos civiles de las minorías; el derecho al trabajo, religión de un reconocimiento digno de sus derechos, frente a la hegemonía de los grupos de poder. Con el fin de evitar la discriminación.

En la Latinoamérica es a partir del reconocimiento de justicia social que demandan las poblaciones originarias (por las condiciones precarias de vida), a consecuencia de la inequitativa distribución de los bienes.

El concepto intercultural nace en Sudamérica (Venezuela), (Mosongi,1970) construyen una visión de interculturación como proyecto pedagógica; que no es aculturación ni endoculturación, en el estado Mexicano se plantea la educación Bicultural y lo intercultural como un enfoque para los vulnerables, en USA como la atención a las minorías; surgiendo las connotaciones de la multiculturalismo.

La interculturalidad es la forma construimos la idea del otro en un proyecto ético político. Su origen viene de la reivindicación de los movimientos contraculturales del 68 (Europa) y atención a las minorías y justicia social. Ambas se fusionan para dar sentido a la atención a la interculturalidad que ya no son propios de las comunidades indígenas sino más bien responde a una atención a la diversidad como una visión del mundo. 
costumbres, las tradiciones, los ecosistemas y demás aspectos propios de la entidad y municipios respectivos". (Ley General de la Educación, 2011).

Para lograr la aprobación de modelos curriculares que respondan a los contextos culturalmente diferentes es prioridad en primera instancia adecuar los contenidos al plan nacional "En los programas de estudio deberán establecerse los propósitos específicos de aprendizaje de las asignaturas u otras unidades de aprendizaje dentro de un plan de estudios, así como los criterios y procedimientos para evaluar y acreditar su cumplimiento. Podrán incluir sugerencias sobre métodos y actividades para alcanzar dichos propósitos." Las sugerencias y métodos, han sido parte del discurso educativo. Por diversas razones las sugerencias a los planes estudios, se ha reducido a la "regionalización de los contenidos" en mención el Artículo 13, ratifica: "Corresponden de manera exclusiva a las autoridades educativas locales, en sus respectivas competencias, las atribuciones siguientes:

I. Prestar los servicios (...) de educación indígena, así como; II.- Proponer a la Secretaría los contenidos regionales que hayan de incluirse en los planes", dejando al profesorado en un proceso burocrático rígido y sistemático.

Los problemas actuales del enfoque intercultural bilingüe son: un diseño curricular que responda a las expectativas del discurso político que contenga como prioridad fortalecer la praxis de la educación intercultural mismos, hacen indispensable prestar mayor atención a las prácticas que se producen en los procesos educativos. Con esta finalidad, se ha reformado el programa de educación primaria 2011, que restableció un apartado para la educación intercultural; replanteado que: "La Lengua Indígena se integra con la enseñanza del Español como segunda lengua, cumpliendo el mandato constitucional de ofrecer una educación intercultural y bilingüe, y de avanzar hacia la construcción de una nación plural; La educación intercultural bilingüe se aplica en 22000 escuelas, aproximadamente, que atienden una matrícula de cerca de un millón y medio de niños. En este universo, el inglés se ofrece como tercera lengua, con su respectiva metodología, de tal modo que durante el ciclo escolar 2011-2012 se pasa de 70 a 200 escuelas donde el inglés se imparte como lengua adicional” (RIEB, 2006). Cumpliendo un mandato constitución de ofrecer una educación intercultural bilingüe para las poblaciones indígenas.

Se incluye como asignatura la lengua materna con fines de práctica social, con base en la observación realizada, las formas en que estos principios se practican en las escuelas primarias indígenas se anclan en procesos propiamente de traducción del castellano y escrituras practicadas 
de acuerdo a las pautas de lenguaje empírico de los hablantes; bailables, representación de altares son formas traducidas en procesos interculturales.

\section{La comunidad escolar de los Ch'oles de Tila}

Las escuelas primarias indígenas observadas, a pesar de pertenecer a la modalidad de escuelas indígenas bilingües ${ }^{4}$ reproducen en su interior practicas cotidianas propias de las escuelas primarias monolingües - plan y programas, guías, Auroch, festividades- el uso de la lengua materna por docentes y alumnos resulta esporádica en el entorno escolar, estableciendo un vinculo en castellano en el proceso de enseñanza aprendizaje. Habitualmente los docentes mencionan la falta del uso de la lengua materna debido a la indisposición de padres al uso de esta. "van a la escuela a aprender cosas nuevas para que puedan salir adelante no para aprender lo que ya saben (se refiere a la lengua Ch'ol)" comentarios que se escuchan a menudo por los tutores de los alumnos. Las afirmaciones vierten la idea de modernidad y progreso al uso del castellano y el abandono de la lengua materna, condiciones que el sistema educativo nacional a intentado resolver mediante las políticas de homogenización ${ }^{5}$, mediante los insumos del: orden

\footnotetext{
${ }^{4}$ En términos de administración la SEP y la DGEI. son instituciones a nivel nacional que se encargan de la evaluación de los servicios, la elaboración de planes y programas, elaboración de reglamentos y normas de funcionamiento, calendario escolar, elaboración y distribución de libros de textos a nivel general y en lenguas indígenas, entre otros. Independientemente que los estados también tengan sus propias estructura y normas de administración. En el Estado de Chiapas se encuentra los S.E.F. (Servicios Educativos Federalizados) cuenta con una Dirección de Educación Indígena quien se encarga de evaluar el funcionamiento de los servicios educativos y prever de recursos material y humano a las poblaciones indígenas; además cuenta con programas como: Culturas populares, Centros de lenguas indígenas, quienes se encargan de difundir y preservar la cultura indígena, y escuelas como la Universidad Pedagógica Nacional y la Normal Indígena Intercultural Bilingüe, etc., las cuales contribuyen a la formación y actualización de los profesores en servicio. Así como programas del PAREB y, cursos nacionales y estatales, que intervienen en la actualización de los docentes en el nivel básico (prescolar, primaria y secundaria).

${ }^{5}$ La propuesta castellanizadora con una percepción de diferencia de los pueblos originarios de la población nacional con fines de integración. El modelo bilingüe, aunque valoraba la importancia de las lenguas de los indígenas, una de las fuentes básicas de la diferencia, buscaba servirse de ellas para facilitar la castellanización (García Segura, 2004:61-81). La educación bilingüe bicultural la lengua y la cultura son considerados en todo el proceso educativo, posterior a ellas la educación intercultural bilingüe para las comunidades indígenas, con la creación de escuelas normales interculturales. La educación bilingüe bilcultural (enseñar el español) se impulsa por los movimientos indígenas que predominaba (1970) y se conduciría para los y con los actores del momento (a reservas del PRI), posterior a ella se promulga lo intercultural (fortalecer la lengua materna) como una manera de ver al otro. Exigen la endoculturación para fortalecer lo propio (intra) el esencialismo estratégico. La inter es una forma de relación entre culturas distintas, no un programa.
} 
jurídico, economía, lenguaje común, y la aplicación del plan y programas educación nacional a los grupos culturalmente diferentes ${ }^{6}$.

El Estado enfrenta un elevado índice de rezago educativo tanto en la población indígena como en la no indígena, Pero la situación de los primeros ha remitido al gobierno a enfrentarlos con estrategias y acciones diferentes a los contenidos o demandas del discurso oficial. La realidad es que las diversas modalidades de educación primaria; primaria federal, primaria estatal y a primaria indígena enfrenta las mismas normas administrativas para la evaluación del sistema educativo sin considerar sus particularidades; lengua, cultura, costumbres y tradiciones.

Por ejemplo los estándares nacionales "miden en una métrica única para toda primaria y secundaría las habilidades cognitivas del alumno asociadas a la comprensión lectora y a la matemática contenidas en los planes y programas de estudios oficiales...Se aplica a alumnos de primaria de los estratos urbano privado, urbano público, rural público, cursos comunitarios y educación indígena...además del examen se aplican cuestionarios para identificar factores asociados al logro". (SEP, 2001).

Las escuelas no son ajenas a estas adversidades, el resto de la población pertenece a comunidades indigenas y la falta de medios de comunicación, su pobreza, su diversidad lingüística y su dispersión son uno de los grandes obstáculos que se han intentado solventar con la apertura de caminos puentes y electrificación a las comunidades más marginadas.

\section{Los Programas educativos para la atención a la diversidad}

Con el objetivo de atender de manera integral los retos de la realidad social del Estado el Gobierno puso en marcha el Programa Estatal de Educación 2001-2006 dicho programa, "Es

\footnotetext{
${ }^{6}$ Se intenta resolver el problema de los diversos grupos indígenas en Chiapas en 1953, a través de la sección de Educación del Centro de Coordinador Indigenista Tzeltal-tzotzil de San Cristóbal de las casas. En 1964 esta sección de educación paso a formar parte del servicio nacional de promotores culturales y maestros bilingües establecidos directamente por la Secretaria de Educación Pública, planteando como objetivo la atención a etnias indígenas existentes en el estado, como son: Tzeltal, Tzotzil, Chol, Zoque, Tojolabal, Man, Kakchikel, Mocho y Maya Lacandón.

${ }^{7}$ Con el Acuerdo Nacional para la Modernización de la Educativa Básica de 1992, el Sistema Educativo Mexicano ha venido experimentando una década de modificaciones y adaptaciones en diferentes órdenes. El 18 de mayo de 1992, se firmó el Acuerdo Nacional para la Modernización de la Educación Básica, entre el secretario de Educación Pública, la dirigencia del Sindicato Nacional de Trabajadores de la Educación y los gobernadores de los estados, bajo tres propósitos esenciales.

Retoma como estrategia el federalismo que consiste en articular esfuerzos y la responsabilidad de cada entidad federativa. Reflejándose en la transferencia de la dirección de las instituciones educativas del gobierno federal a diversas entidades del país con los que la SEP había venido, de cierta forma, dirigiendo los servicios educativos de los estados predominando la implantación de proyectos: la desconcentración de las tareas administrativas a las 
una instancia colegiada que tiene como objetivo general coordinar la operación de las políticas para el desarrollo de la educación básica estableciendo consensos, y concretando acciones que involucren a todas las instancias que realizan educación básica en el estado” (SEP, 2001). Ratificando la falta de coordinación en los aspectos administrativos, debido a la existencia de dos coordinaciones y direcciones, provocando sobrepoblación de personal y materiales para la homologación de una misma cobertura, sin explicar estrategias para la efectividad del programa, pero reconociendo el proceso de competitividad del magisterio como requisito administrativo para mejorar su ingreso económico. ${ }^{8}$

Uno de los puntos esenciales es el "reconocimiento de una educación intercultural que favorezca el respeto a la diversidad de los grupos existentes" ", así como la revaloración de la cultura, la identidad y la lengua, basada en la reformulación del currículo educativo a situaciones especificas de cada grupo ${ }^{10}$. En el caso de la lengua materna Ch'ol se restringe su uso a situaciones informales ya que Educación Indígena ocupa los Planes y Programas Nacionales provocando un real desfase entre lo local y lo nacional. Al respecto Zendejas (2012) cita a Zimmermann:

El concepto de educación bilingüe intercultural y el modelo y práctica a que ha dado lugar, se ha convertido en un lema político muy de moda, a tal grado que no falta en casi ningún discurso de política educativa indígena, llegando incluso a imponerse como

entidades regionales, sin la apertura de proyectos autonomistas de percepción pedagógica propia, ${ }^{7}$ por ello se reitera el respeto a los preceptos establecidos en la Ley General de la Educación de 1993 y el que suscribe en el Articulo $3^{\circ}$ Constitucional.

Con el fin de corregir el centralismo y el burocratismo que aqueja el SEM, el gobierno federal y estatal ha celebrado convenios para concretar las respectivas responsabilidades de cada uno en la conducción y operación de la educación básica y normal. Por eso es que a partir de la firma del acuerdo corresponde a los gobiernos estatales encargarse de la dirección de los establecimientos educativos cómo también organizar y proponer alternativas educativas para el estado siempre y cuando este acorde a las exigencias del ANMEB.

${ }^{8}$ Entendiendo por competitividad el cumplimiento de la normatividad para incorporarse o ascender a una de las categorías de la Carrera Magisterial.

${ }^{9}$ Op. cit.., pag. 4.

${ }^{10}$ El Programa Nacional de Educación 2001-2006 (PNE), pese a su desorden e inconsistencia interna, se fijó objetivos muy importantes, considerados estratégicos: garantizar la equidad y la justicia educativas, mejorar la calidad del proceso y el logro educativos, y transformar la gestión institucional para hacer de la escuela el "centro de gravedad" del sistema educativo... ni más, ni menos. A casi tres años del actual gobierno es evidente la ausencia de políticas centrales para hacer realidad este discurso.

Muchos de los avances conseguidos durante la década pasada en varios campos de acción de la política educativa se debilitan paulatinamente o se han diluido, ya sea por la ausencia de acciones sostenidas y fundamentadas para su consolidación o por la difusión o puesta en marcha de medidas aisladas que desorientan el trabajo educativo cotidiano. En otros casos, como el programa de carrera magisterial o los programas compensatorios --pese a su evidente falta de eficacia para mejorar la calidad y la equidad de la educación básica-- simplemente gobierna la inercia burocrática, atribuible al desinterés y a la ignorancia que privan en el equipo del actual encargado del despacho de educación pública. 
modelo de intervención educativa oficial en muchos países con minorías étnicas amerindias como Bolivia, Colombia, Ecuador, Perú; mientras que han quedado como propuestas políticas en Honduras y México (Zimmermann apud ZENDEJAS, 2012).

En particular ambas escuelas indígenas de la zona de estudio fue adoptado medidas de "cambios" con la reproducción de los contenidos del programa nacional como: la reformulación de los contenidos y materiales educativos, que a propiciado que el entramado de las relaciones laborales sean más rígidas en la aplicación de los programas establecidos.

La autonomía del profesor frente a la enseñanza se ve "menos tensa" al pasar de la rigurosa secuenciación temática a elección de temas de intereses, que de alguna manera congratula la dinámica participativa en el aula bajo métodos y estrategias menos ortodoxas propuestas por los “expertos” (plan y programa nacional).

En estas tareas ${ }^{11}$ diseñadas para el docente se han referenciado las escuelas urbanas y rurales "El tratamiento homogéneo de la realidad pedagógica o institucional es claramente distinta - como son la urbana y la rural- además de destacar el criterio administrativo, prioriza de hecho a la escuela urbana como referente de toda la realidad que se quiere regular o dicho en otros términos ignora la dinámica propia, la calidad y cantidad de trabajo que técnica e institucionalmente genera la escuela rural, precisamente por ser rural.” (Ezpeleta, 1991).

En éste sentido, las normas institucionales son un elemento de regulación y control que posibilita descubrir e interactuar con su verdadero escenario de acción y, es a través de éste que se comienza a introducirlos en las diversas actividades, por lo que el escenario estipulado se convierte en el trabajo real que ellos deben desempeñar cumpliendo con el rol que les ha sido asignado por la institución.

Existe una gran supervisión y control para que no rompan con los mandatos y reglas de la institución, buscando así que lleguen a ser sujetos institucionales trabajadores y de provecho.

El control del espacio en el que realizan sus actividades (aulas, direcciones, departamentos), así como del tiempo que invierten en cada una de ellas, son parte de las normas que contribuyen a que éstos internalicen no sólo las formas de vida de su grupo sino que también contribuye a formarlos como sujetos individuales.

\footnotetext{
${ }^{11}$ Inscripción de los alumnos, Estadísticas 911.3 de inicio de cursos. (alumnos inscritos), Estadística bimestral en octubre, diciembre, febrero, abril y junio, Resultados bimestrales de la evaluación del grupo, Formas IAE correspondientes a los grados de primero a quinto, REL 1 y 2 para sexto grado, Boletas de calificaciones del grupo asignado, Estadísticas 911.4 de fin de cursos.
} 
De esta manera se logra explicar cómo los sujetos institucionales tienden compartir, ideas, comportamientos y actitudes similares que dan solidez a su gremio pero que se refleja de manera independiente en la personalidad de cada individuo.

Retomando los procesos de que legitiman la institución: habituación, tipificación y el control es el fin último del proceso socializador, ejercido por las normas institucionales, está dirigido hacia un adiestramiento gradual para que cumpla con las normas y pautas de conducta establecidas indispensables para su actuación.

En éstos procesos los sujetos institucionales juegan un papel determinante, pues; como ya se dijo anteriormente es ahí donde se observa que la cultura del alumnado supone un verdadero problema dentro de la vida escolar que agudiza.

Esta educación busca la integración de los nuevos miembros (hijos) a la vida familiar y social; en este sentido, la cultura "es el modo de vida de los individuos, comprende un acervo complejo de formas instituidas de conducta, elementos materiales elaborados naturalmente e instituciones sociales que permitan el acomodo del individuo en la sociedad; se encuentra en pleno movimiento ya que adquiere significado en la interacción del hombre con su medio, en contacto con generaciones pasadas, presentes y futuras" (Escalante y Miñano 1982: 22).que posee el grupo familiar determina las características de este proceso educativo, sus modos de proceder, actuar y pensar están sustentados con los patrones culturales que han pasado de generación en generación y que los hace identificarse como miembros de una comunidad específica con modos y formas propias de vivir y de relacionarse con las demás personas del pueblo.

El proceso educativo se prolonga durante toda la vida de los individuos, alcanzando un notorio énfasis en los primeros años, en donde se absorbe gran parte del bagaje cultural del grupo social al que se pertenece, ya que "una característica básica de la condición social del hombre es que la cultura es aprendida y no heredada genéticamente" (Cisneros, 1997:10).

El proceso de aprendizaje de la cultura es llamado endoculturación, ésta es la que permite el hecho de que una cultura mantiene una forma identificable que pasa de generación en generación. Se consigue en gran medida por medio del simbolismo del lenguaje. Proporciona el mecanismo que hace posible los cambios que determinan la historia de cada cuerpo de costumbres. El proceso de endoculturación, que significa condicionarse a la totalidad de una cultura y no a un segmento de ella, ayuda a resolver la aparente contradicción de que la cultura es estable, y no obstante, al mismo tiempo, está en continuo cambio. (Herskovits, 1981: 679) se da 
mediante una adaptación y condicionamiento hacia las formas de vida de su familia que lo llevarán, durante toda su vida, a aceptar valores, normas, creencias y costumbres preestablecidas desde antes de su nacimiento, a afirmar su identidad, Pérez (1990) Considera que la identidad es la autoafirmación consciente frente a lo que excluye como diferente de lo que se afirma en un proceso comparativo. Implica procesos de adscripción en los cuales los sujetos crean, seleccionan o afirman rasgos o marcas de identificación mediante una reelaboración simbólica que les permite aglutinarse como unidad y actuar sobre un universo de elementos culturales que consideran propios y que les permite caracterizarse como diferentes a otros y contribuir a la estabilidad cultural.

\section{De cara a la realidad}

En todo este proceso, el simbolismo del lenguaje tiene un papel determinante en la educación de los hijos, pues a través de éste se comparten experiencias, se instruyen y alientan a los hijos a desarrollar aptitudes y habilidades en beneficio personal y familiar, se comparten experiencias, chistes, mitos y leyendas del grupo cultural, se forman valores, se comparten los conocimientos y para ello el padre y la madre, por cultura, tienen su espacio y momento de intervención con los hijos. Es en éste sentido que se comprende lo que comenta Kisho [LM.Chol.Of.MB.]: ${ }^{12}$

[...] hay espacios en ese trabajo donde de repente se nos sale la palabra a comentar alguna cosa, sobre trabajos, sobre relación de nosotros con la vida cotidiana que vamos a llevar y sobre el respeto con las personas que debemos tener ante la sociedad [...] nos orientaba de acuerdo al sufrimiento tamién que él staba viviendo (el papá) [...] gracias a él [...] con sus orientaciones pues yo he podido llegar hasta donde stoy [...] en cuanto a mi mamá casi no, no tuvo ese, ese orientación hacia mí, este, si lo fue pero muy poco [...] la orientación de mi mamá fue un poco así más religiosa [...] me decía que era importante respetar a los demás porque ese es lo que quiere Dios [...] respetar la vida en la sociedad y que es necesario que participemos en los cultos religiosos que las familias en donde participa $[\ldots]^{13}$.

Es necesario dejar claro que el lenguaje es el agente más adecuado para la endoculturación; por ello las personas que hablan la misma lengua tienen una manera semejante

\footnotetext{
${ }^{12}$ Las siglas LM., Of., MB., significan Lengua Materna, Oficio, Maestro Bilingüe, respectivamente. Estas serán las mismas para los entrevistados.

${ }^{13}$ La transcripción es "cercana a la palabra", es decir, respetando la manera de hablar del entrevistado.
}

R. Articul.const.saber, 2019, v.4: e57997 
de pensar, de comportarse y de sentirse (Cobos, 1991: 84). En la familia Ch’ol su lengua materna no sólo actúa como instrumento de comunicación, sino que también juega un papel importante en la transmisión, conservación ó transformación de su cultura. Para Leibniz (1999: 105) el lenguaje no sólo es vehículo de un pensamiento, sino medio determinante de la misma etnia. Razón por la que, a pesar de la aceptación del español, han implementado mecanismos que les permite garantizar la persistencia del chol como uno de los elementos más importantes que les da identidad cultural y que les permite conservar y heredar a nuevas generaciones las ideas y costumbres propias de su grupo étnico. ${ }^{14}$ Hablar en lengua materna en el interior del hogar y en las relaciones que se establece en su exterior con sujetos ajenos a ella pero pertenecientes al mismo grupo étnico favorecen este fin, especialmente el que muchas de las mujeres sean monolingües (únicamente hablantes de la materna); éste fenómeno obedece a que ellas son el medio idóneo para transmitirla y preservarla, pues, son quienes mayor responsabilidad y contacto tienen con los hijos en sus primeros años, son las encargadas de enseñarles sus primeras palabras garantizando de esta manera el aprendizaje y continuación de su lengua.

\section{Procesos de aprendizaje; la observación y los juegos}

Cada miembro de un grupo social también es individualmente enculturado, Habermas (1994: 25), entiende por enculturación (formación) es el proceso gracias al cual, en el ámbito de una determinada tradición cultural, una persona se configura como sujeto capaz de lenguaje y acción $\mathrm{y}$, consecuentemente, capaz de mantener o renovar los saberes transmitidos, desde el momento mismo de su nacimiento conforme a patrones culturales, de conducta y a los valores de su grupo en la interacción cotidiana con los demás integrantes de su comunidad, pero particularmente con los miembros de su familia, por ser con quienes inicia su proceso de socialización. Dicha socialización, entendida como parte del proceso de educación familiar y de la convivencia con la comunidad, es el modo inconsciente de aprender la lengua materna, las formas de vida del grupo, sus valores, ideas, actitudes y costumbres como resultado de la

\footnotetext{
${ }^{14}$ Hoy en día una gran mayoría de la familia Ch’ol de este pueblo son bilingües (jóvenes); aquí se me hace importante destacar una situación peculiar que se está presentando en los Ch’oles con la aceptación del español; con él no sólo obtienen una manera de comunicarse con los demás sectores sociales de habla hispana sino que, sin darse cuenta, ellos aceptan ideas y costumbres de los otros, lo que puede llegar a traducirse en un grado de aculturación o pérdida de su identidad.
} 
interacción con otros sujetos y principalmente con el padre y la madre, quienes mediante los roles que desempeñan en esta transmisión de conductas sociales, culturales y sexuales permiten a sus hijos obtener los distintos roles y patrones de comportamiento para que pueda satisfacer sus necesidades y por ende sobrevivir dentro de su grupo étnico y social.

En las familias ch'oles, los padres tienen social y moralmente la responsabilidad de formar y educar al hijo que pertenezca a su mismo sexo y con el sexo opuesto solo intervienen de manera indirecta; aunque los primeros años de infancia está básicamente dominada por la madre. Esta situación es fácilmente identificable cuando Kisho [LM.Chol.Of.MB.] comenta la relación que él estableció con cada uno de sus padres:

[...] mi relación con mi mamá es, casi era un poco distanciado que digamos, e, con quien más me apegaba yo es con mi papá [...] ella casi nunca me dijo que, qué cosa quería yo ser, de que sí se preocupó por nosotros [...] con mi mamá casi no he salido a veces mi papá he salido con él pero no es porque hay ese gusto, no es porque lo, este, lo decida él o lo decida yo sino que cuando tengamos algo que hacer junto los dos [...] empecé a trabajar con él [...] siempre con mi papá pues aprendí a distribuir mi tiempo, si, él es, me ayudó mucho a saber orientarme con el tiempo y distribuir cuantas horas me llevaba cada trabajo [...] en relación a mi mamá pues casi no aprendí a trabajar mucho con ella las cosas que realizaba $[\ldots]$.

El proceso de aprendizaje en primer momento se realiza mediante un proceso fundamental denominado mimesis, que puede identificarse, en cierto sentido, con la imitación, pues después de observar una actividad, actitud o palabra, el individuo trata de reproducirlas pero no exactamente de imitarlas. (Cisneros, 1990: 56). Es así como aprende midiéndose con las situaciones de la vida cotidiana dentro de su espacio social.

Por lo tanto, el aprendizaje de los papeles masculinos y femeninos se realiza mediante éste proceso; en él se estimula el otorgamiento de responsabilidades reales, por lo que a la edad de 3 a 4 años el niño Ch'ol comienza a realizar algunos de los oficios "propios de su sexo"; asimismo, aprende por imitación (mimesis) todos los demás esquemas de conducta. Las formas en que se distribuyen las actividades están condicionadas según el sexo y edad, él ya tiene la actividades laborales especificas aunque limitadamente por sus capacidades físicas, y a medida que va creciendo sus obligaciones y responsabilidades también crecen (Bertely, 1997; Díaz, 2001). Al respecto Shep: comenta:

Cuando de muy, muy chiquito, de edad de 3 años, como yo vivo en el cafetal ahí mismo salen ellos a, a ir recoger el café; ya de 3 años, de 4 años ya lo pueden levantar el café es ahí donde empezaron a sentir el sufrimiento [...] cuando 'stán aquí pues, como 'stán 
chiquitos pue' no pueden traer cosas y se quedan en la casa no más cuando quieran se van al cafetal y aquí lo ayudan a su mamá a escoger café, a levantar café, ese es todo lo que le hacen, a desgranar maíz, algunos a cargar frijoles, eso es todo lo que hacen los ñiños [...] ya edades de 6,7 años [...] todo el tiempo se iban al cafetal [...].

A pesar de que los niños Ch'oles realizan actividades de apoyo en las labores del campo durante largas jornadas, la vida de juego es rica y activa para conocer el medio en el que se desenvuelven y en el que tendrán que trabajar para ayudar al bienestar de su familia; Kisho [LM.Chol.Of.MB.] dice: "[...] pues nuestro centro de diversión era el cafetal, el patio de la casa". En éste sentido, el juego no sólo es un elemento de distracción y socialización sino también una herramienta de enseñanza-aprendizaje que posibilita a cada uno descubrir e interactuar con su verdadero escenario de acción y, es a través de éste que desde muy temprana edad se comienza a introducirlos en las diversas actividades, por lo que el juego se convierte muy pronto en el trabajo real ${ }^{15}$ que ellos deben desempeñar cumpliendo con el rol que les ha sido asignado socialmente.

\section{El control y la obediencia en la regulación de actividades}

Existe una gran supervisión y control (durante toda la etapa de su crecimiento) para que no rompan con los valores y reglas de la familia, buscando así que lleguen a ser personas trabajadoras y de provecho, razón por la que se les priva de ciertas diversiones que puedan influir de manera negativa en la formación de su personalidad; Shep [LM.Chol.Of.C.] comenta algunas de las reglas en su familia:

\footnotetext{
${ }^{15} \mathrm{El}$ trabajo infantil tiene connotaciones que van desde un proceso socializador que fomenta la participación y la cooperación así como el puente en el desarrollo de habilidades, hasta la explotación de la mano de obra de los infantes.

La Organización Internacional del Trabajo (OIT) lo define como "toda actividad económica llevada a cabo por personas menores de 15 años de edad, sin importar el estatus ocupacional (trabajo asalariado, trabajo independiente, trabajo familiar no remunerado, etc.). Ello no incluye los quehaceres del hogar realizados en su propio hogar, excepto donde los quehaceres del hogar puedan ser considerados una actividad económica -como, por ejemplo, cuando un niño dedica todo su tiempo a estos quehaceres para que sus padres puedan trabajar fuera del hogar y ello signifique privarlo de la posibilidad de ir a la escuela".

En cuanto El Sistema Nacional para el Desarrollo Integral de la Familia (DIF) como "aquellas actividades que desarrollan las niñas y los niños en el marco de la economía formal o informal para su propia subsistencia o para contribuir a la economía familiar al margen de la protección jurídica y social prevista en la ley" La Constitución Política de los Estados Unidos Mexicanos establece la prohibición del trabajo infantil (Artículo 123).

III.- "Queda prohibida la utilización del trabajo de los menores de 14 años. Los mayores de esta edad y menores de 16 tendrán como jornada máxima la de seis horas.” Esta prohibición del trabajo infantil por la Constitución y las leyes laborales no impide en sentido estricto que los menores estén excluidos de las actividades económicas.
} 
[...] de que vayan a jugar solos no [...] los llevo a ellos y al regresarme se regresan conmigo aquí en la casa así como les digo sus trabajos, sus tareyas, claro que salen a jugar sus canicas por allí, como son dos se criaron con ellos se jugan, se ponen a jugar a veces con el profesor Adolfo también que son sus primos, se vienen a jugar con ellos pero aquí en el patio nunca salieron a la calle por eso 'stan como 'stan orita, nunca estuvieron endrogados, nunca se fueron a la luz y sonido, nunca stuvieron en el baile ni salieron a pasear na' mas así en la calle [...] yo les digo pues que no sirve que salgan 'stán jóvenes, que no es para ellos en las calles que 'stán ahí vagando [...].

El control del espacio en el que realizan sus actividades (incluyendo el juego), así como del tiempo que los hijos invierten en cada una de ellas, son parte de las normas que contribuyen a que éstos internalicen no sólo las formas de vida de su grupo familiar sino que también contribuye a formarlos como sujetos individuales (a constituir su personalidad) capaces de tomar sus propias decisiones respetando los valores que les fueron inculcados.

De esta manera se logra explicar cómo los miembros de un grupo familiar tienden compartir cosmovisiones, ideas, comportamientos y actitudes similares que dan solidez a la unidad familiar pero que se refleja de manera independiente en la personalidad de cada individuo. En los entrevistados se hace evidente esta situación al notarse un sentir común de lo que para ellos es bueno o malo, del valor del respeto, de lo que es una amistad apropiada, de la importancia de la obediencia, entre otras cosas que aprendieron de sus padres y que tratan de llevar a cabo independientemente de las características de su personalidad que los constituye como individuos autónomos.

Aunque los sujetos sean educados dentro de los parámetros de su cultura, esto no quiere decir que no sientan rechazo hacia alguna parte de ésta y ocasione que actúe procurando evitarlas o negarlas; contrariamente, lo aceptado se establece como rutina proporcionando la estabilidad cultural. Es la aptitud de aceptar y rechazar la que va a permitir los cambios y renovaciones de una cultura, de ahí que la cultura no sea estática. (Change, 1991: 72). Es así como podemos ver también que ellos son capaces de perpetuar o modificar sus tradiciones y costumbres, sus formas de vida; es decir, su cultura, esto como resultado de los procesos de endoculturación y enculturación que están íntimamente relacionados en todas las etapas de la socialización del Ch'ol con su familia y con la sociedad en general.

Durante toda la vida, la observación como técnica de conocimiento es la que permitirá contemplar y aprehender la realidad del contexto en el que se desarrolla su modo de vida, 
asimismo; permite la percepción y el conocimiento de las formas de vida de su grupo al mirar, examinar y contemplar cada una de las actividades de otros sujetos, sus relaciones, actitudes, formas de trabajo y prácticas en general y la imitación posibilita el aprendizaje y el conocimiento de las formas y modos de vida del grupo familiar, posibilita la reproducción de los patrones culturales establecidos al repetir actitudes, formas de trabajo, modales, etc., tomadas del comportamiento de un modelo (otro sujeto). A través de ésta el sujeto iguala o hace corresponder sus propias acciones con las acciones de otros, ambas serán las principales técnicas de conocimiento aunque acompañadas de explicaciones instructivas de los padres para lograr que los hijos se adapten a las técnicas de trabajo, a los modos y formas de vida del grupo familiar al que pertenece.

A través de la interpretación de la información recabada, los niños Ch'oles de Tila juegan con objetos que encuentran en el medio en donde se desarrolla su vida familiar (sus pocos juguetes pueden ser las canicas, palos, piedras, los propios instrumentos de trabajo de los padres, etc.) pues la mayoría de éstos carecen de muñecos y otros juguetes con los que juega un niño mestizo.

Mediante el juego también imitan a sus padres en el trabajo, los niños al padre y las niñas a la madre; pero tras todo lo que se ha dicho sobre el juego se encuentran que ambos son procesos interactivos que refuerzan los procesos de apropiación de las actividades laborales en el campo, esto se hace evidente cuando Shep [LM.Chol.Of.C.] orgulloso afirma:

[...] pues como ellos nunca les gustaron jugar, ya edades de 6,7 años cuando ya 'stán de segundo, de tercero de primaria todo el tiempo se iban al cafetal, peor orita que estos meses que hay cacaté, que hay nanch que les gusta mucho para ellos esos, ellos lo llegan a traer aunque sea por morralito, ahí vienen con sus frutas, ahí vienen con sus naranjas, con sus limas, con lo que encuentran en el cafetal, ese es lo que les gustaron, si, y por eso me gustó mucho ellos porque cuando voy en la junta ellos me ayudan a traer algunas cosas para la casa, para la comida, encuentran plátano pues hay vienen ya con sus pencas de plátano, si, mientras yo 'stoy en mi reuñión, mientras yo 'stoy haciendo otra cosa, y así fue como me dio mucho gusto tenerlo a ellos [...].

La transmisión de los saberes no es deliberada ni sistemática, se realiza mediante la imitación de las actividades, como la inculcación de los principios del trabajo mediado por el ejemplo del padre. Este mismo suceso se hace evidente cuando Kisho [LM.Chol.Of.MB.] sonriente afirma haber sido muy obediente y tranquilo pero reconoce haber "abusado" del tiempo en que jugaba, cuando ya se le habían encargado ciertas labores:"[...] a veces lo agarrábamos más 
juegos menos en los trabajos". También podemos observar esto cuando él comenta con tranquilidad y énfasis lo siguiente:

[...] Cuando stamos chamacos se nos olvida las cosas [...]cuando uno, pues no obedecía, entonces sí a veces ponía sus condiciones [...] la educación en mi casa a esta altura lo considero como favorable [...] la verdad antes no [...] yo lo sentía un poco drástico [...] a esta altura pues yo stoy agradecido [...].

Pero Tyeko [LM.Chol.Of.MB.], otro de los informantes, el más joven, rememoraba esta situación mostrando cierto desagrado y resentimiento:

[...] para jugar casi no tuvimos ni tiempo para eso desde la niñez porque no podíamos jugar, nunca tuve juguetes en mi niñez por eso a veces ahora lo que me gusta lo compro, porque no, no tuve esa oportunidad de jugar en la niñez, tuve, nos daban juguetes (en la escuela) pero no lo podíamos jugar por el trabajo más que nada, quiera uno jugar pero a veces te regañan por estar jugando a que no hagas caso a lo que tienes que hacer, una vez tuve un, nos regalaron una, un carrito pero por no hacer caso nos la aventaron y hasta ahí acabó el juguete...si!!, o sea que se siente uno mal pero no lo expresa uno porque, por el temor de que lo peguen a uno o no, y entonces ya queda uno a trabajar pero sin ganas [...] ella (hermana) casi no tuvo espacios para jugar tampoco [...] o sea hubo momentos de juego no digo que no, pero no mucho tiempo, no todos los días sino que tiene un cierto límite na' más podía jugar uno si no están los papás porque se siente un poco libre $[\ldots]$.

Es evidente que para las familias Choles el modelo de hijo ideal es trabajador, obediente, responsable y no pierde su tiempo con juegos; sin embargo, no se le exige que lo deje completamente sino que se le da pequeños momentos para su distracción; pero a los padres les agrada que sus hijos a muy temprana edad sean capaces de realizar los trabajos propios de su sexo, de ahí que los niños los acompañen a la generalidad de oficios y más tarde deben de ser capaces de ir solos a trabajar en el campo o en el caso de las mujeres deben ser capaces de responsabilizarse del hogar.

Aunque el juego no es una actividad limitada a los primeros años de la infancia se le encuentra asociado con éstos; pues el niño Ch'ol se convierte muy pronto en un "pequeño adulto" dadas las responsabilidades que le son asignadas en el hogar, con las cuales contribuye al bienestar familiar y que de una u otra manera limitan en gran medida sus momentos de juego. Sin embargo, aquí debemos tener presente que el niño Ch'ol no es un agente pasivo en el proceso de su educación, pues el medio social, cultural, psicológico e ideológico en que se desenvuelve lo impulsa a conquistar su estatus de adulto a muy temprana edad. (Cisneros, 1990: 55) 
Para muchos estudiosos de las comunidades indígenas, el pronto abandono de la infancia no es tan dramático, pues el individuo es compensado con el reconocimiento social del grupo que le permite tener mayor injerencia en diferentes ámbitos. Pero, aun cuando como hijos se muestren orgullosos de haber obtenido las habilidades necesarias y propias del rol que desempeñan, en su proceso de aprendizaje descubrieron que trabajar en el campo no es fácil, al menos la mayoría de los entrevistados mostraron sentimientos ambivalentes al respecto. De modo parecido, el trabajo en el hogar tampoco se muestra fácil para las mujeres, ellas deben levantarse más temprano que el hombre para comenzar las labores del hogar y preparar la comida; la madre prepara a la hija para que desde temprana edad comience a encargarse de todas las tareas de la casa y de las demás actividades que ella realiza, lo cual sirve como un entrenamiento para que lleguen a ser buenas esposas. También deben aprender algunas actividades agrícolas para apoyar en el trabajo a los hombres, pues la mujer Ch'ol no sólo se dedica a las labores domésticas sino que también debe contribuir a las labores del campo en sus tiempos libres o de cosecha, además de participar en la comercialización de los productos cosechados. Al respecto algunos testimonios de los entrevistados respecto a la contribución del trabajo de las mujeres para el bienestar familiar:

[...] teníamos que cosechar lo que es el café a como dé lugar [...] íbamos todos, quedaba cerrada la casa $[. .$.$] porque tendría que levantarse a las, a las 4$ (su hermana) para preparar todo [...] [Tyeko.LM.Chol.Of.MB.].

[...] a veces tenía que ir a trabajar con mi papá por nosotros (su mamá), tenía que ayudar a recolectar la cosecha de café, de frijol, sí, entonces a veces ella salía a, a vender esos productos [...] [Kisho.LM.Chol.Of.MB.].

[...] gracias a Dios encontré una mujer que me dio fuerzas [...] porque también ella trabajó mucho [...] no mas se ayudaba a su mamá (hija), se, se levanta temprano las 4 de la mañana a moler pozol y hace la tortilla a veces y como ella también le gustó pues, este le, a trabajar en la casa, le gustó y na' mas le decimos que se levante y sí se levanta, si, ahí stá trabajando, terminando a hacer eso ya empieza a hacer su trabajo [...] [Shep.LM.Chol.Of.C.].

Estas características propias de la educación de las familias Ch’oles de Tila hacen que se constituya como una unidad, Modiano (1982: 37) considera la familia como una unidad en donde cada uno de sus miembros contribuye en la medida de sus posibilidades; es una unidad porque actúa como un grupo compacto guiado por los patrones propios de su cultura que le permiten garantizar su supervivencia, pues aunque en ella existe una división del trabajo, no persigue fines de explotación sino de preparación para que cada uno de sus miembros contribuya al bienestar familiar en la medida de sus posibilidades; lo cual, no sólo se ve reflejada en la ayuda 
económicas de todos sino también en la participación en todos los demás ámbitos (político, social, religioso) en que la familia participa.

La vida pública que se da en las organizaciones políticas, reuniones ejidales, pertenece principalmente al hombre; a la mujer le corresponde las actividades religiosas en las que tendrá que educar a sus hijos para que participen en ellas desde temprana edad. La dirección del hogar es fundamentalmente responsabilidad del padre; sin embargo, la toma de una decisión tan importante para la vida familiar se realiza consultando a la mujer en la intimidad del hogar, al menos en esta familia con quienes se realizó el trabajo de campo; aún más cuando estas decisiones significan romper con patrones culturales establecidos por el grupo Ch'ol.

De acuerdo con su cultura, las familias Ch'oles tienen un gran número de hijos, pues el tamaño de la familia está relacionado con las necesidades de trabajo familiar y con las actividades sociales que garantizan la seguridad y supervivencia del grupo. ${ }^{16}$ Pero factores asociados a la escasez de tierras, la falta de recursos económicos por el bajo precio de sus cosechas y por la explotación que sufren como mano de obra barata, entre otros, no permiten la autosuficiencia del grupo familiar. Son estas cuestiones las que de alguna manera obligan a los Choles de Tila a aceptar la planificación familiar como el mecanismo que ayuda a reducir estos problemas; consideran que al tener pocos hijos sus necesidades serán menos y podrán ofrecerles una mejor condición de vida. Es en este sentido que Shep [LM.Chol.Of.C.] explica sus razones:

$[\ldots]$ no quiero que ellos van a sufrir como yo stoy sufriendo [...] no quise tenerlo mucho [...] teniendo bastante no se puede [...] quise tenerlo lo que tengo nada mas porque tuve en la mente levantarlo, cambiarle el oficio a ellos [...] porque del problema que hay en el campo, en este ejido que el terreno ya no estiramos [...] ya no podemos tener mas [...] en el campo ya no van a poder vivir [...] ese terreno que tengo yo quizá van a tener un pedazo pero ya no da abasto para que puedan sembrar [...].

A pesar de que la planificación familiar han ganado espacios dentro de la comunidad indígena de Tila, existe todavía quienes se resisten a la idea de decidir cuantos hijos tener, porque para ellos es algo que solo a Dios le corresponde determinar. Como formar familias numerosas es una cuestión cultural, tomar la decisión de planificar la familia rompe estos esquemas culturales (al igual que al aceptar que los hijos vayan a la escuela) de los Ch'oles y ocasiona conflictos en

\footnotetext{
${ }^{16}$ La significación psicológica que tienen los niños para sus padres es algo que éstos no pueden dejar de lado. Una familia con muchos hijos tiene mejores oportunidades de satisfacer sus necesidades vitales puesto que su unidad económica es mayor y más fuerte. Todo ello repercute en la forma de seguridad psicológica y personal de todos los miembros de la unidad familiar. (Cisneros, 1990).
}

R. Articul.const.saber, 2019, v.4: e57997 
las relaciones con parientes y con los demás miembros del grupo étnico al que pertenecen. Shep [LM.Chol.Of.C.] algo rencoroso recuerda los problemas a los que él se ha enfrentado a partir de cuando tomó ésta decisión:

[...] Yo cuando planifiqué mi familia pues tuve muchos problemas, mi familia no me quieren ver así que planifiqué mi familia porque soy un haragán o no 'quero' trabajar, mantener mis hijos así [...] sentí, pero de ahí me superé y no, no me quise quedar donde 'stoy 'stuve que si seguir, este, a mandar estudiar mis hijos [...] mas me seguí pa' remostrar que sí vale la pena porque hice la planificación de mi familia para que ellos también den cuenta que si la verdad, este, quieren superarse pero que midan cuantos hijos pueden tener, no que van a tener un montón como pollos y después ya no pueden mantener [...] hasta orita pues si ¡sí te echan en cara...ya tienes todo! [...] casi no muy me hablan pues todos [...] tienen rencores, me hablan pues pero así, así nada mas como que date cuenta que no doy cuenta pero si le doy cuenta porque yo siempre lo escucho como dicen, así es[...] $]^{17}$.

Su aceptación está ligada al deseo de un modo de vida diferente que posibilite mejores alternativas para la familia, pero sobre todo un mejor futuro para los hijos y que se refuerza con el deseo de obtener los beneficios que posibilita el asistir a una escuela. ${ }^{18}$

Retomando los aspectos de su educación familiar, vemos que el fin último del proceso socializador, ejercido por los padres del niño Ch'ol, está dirigido hacia un adiestramiento gradual para que cumpla con las normas y pautas de conducta establecidas por el grupo familiar, en un intento de proporcionarle los elementos necesarios e indispensables para su actuación dentro de la sociedad.

\section{Reflexiones finales}

Para Habermas (1994), la enculturación o formación, y la socialización como procesos de aprendizaje permiten a las personas adquirir las competencias necesarias para interactuar y definir sus motivos de acción, y gracias a éstos el individuo queda estructurado y penetrado por

\footnotetext{
${ }^{17}$ Este lenguaje tergiversado del uso del español es producto de la constante necesidad del indígena de establecer relaciones a través de un lenguaje que no le es propio (español) pero que se le impone, mediante las políticas gubernamentales, como uno de los elementos fundamentales para crear vínculos con el resto de la sociedad nacional en condiciones "más igualitarias". La castellanización provoca un bilingüismo cuyo problema está relacionado con el arraigamiento y vitalidad de la lengua materna que dificulta el uso del español, dando como resultado un grado de dificultad de expresión, coordinación y comprensión de un lenguaje que le es ajeno y el cual busca su sometimiento lingüístico.

${ }^{18}$ Contrariamente a su cultura, las posibilidades de que los hijos de las familias numerosas asistan a la escuela se reducen al tener todos que trabajar en el campo para poder subsistir.
} 
plexos de sentidos culturales y sociales, es decir, se configura como persona. Estos procesos, al igual que la endoculturación, están presentes en todas las familias (mestizas y Ch’oles), en cualquier tipo de sociedad y contexto; la diferencia del modo en el que desarrollan radica en el tipo de cultura a la que pertenece el sujeto.

Siendo la enculturación el proceso gracias al cual una persona se configura como sujeto capaz de lenguaje y acción (en el ámbito de su cultura), y la endoculturación la adaptación a la forma de vida del grupo en que se encuentra y que se da durante toda su vida (inconsciente en la infancia); es evidente que a través de estos procesos también adquiere la capacidad de mantener o renovar los saberes y formas de vida transmitidos por su cultura.

En éstos procesos la familia juega un papel determinante, pues; como ya se dijo anteriormente es ahí en donde inicia su proceso de socialización y, es gracias a ésta que una persona establece una red de interacciones y relaciones con los demás miembros del hogar que le van permitiendo irse constituyendo como un individuo más del grupo familiar y al mismo tiempo, a través de ésta, comenzar a establecer contacto con el resto de la sociedad, posibilitando la formación de una persona con capacidad de acción para mantener o renovar su cultura.

El desarrollo de cada uno de los procesos antes mencionados, tienen lugar en el diario vivir de todos y cada uno de los sujetos de un grupo familiar y de la sociedad en general; es la cotidianidad en la que se desarrolla su modo de vida la que determina las características de éstos proceso y permite a cada individuo obtener experiencias formativas de su personalidad mediante sus vivencias y mediante las relaciones de él con los otros. No hay que olvidar que su vida cotidiana esta condicionada por los patrones culturales impuestos en su grupo familiar, social o étnico al que pertenece.

Todas las familias (mestizas e indígenas) comparten o poseen estas características de formación y educación para cada uno de sus miembros. Sin embargo, la diferencia de las familias Ch'oles respecto de las mestizas está expresada en formas peculiares como su lengua, organización social y familiar, costumbres, rituales, vestidos, etc., propios de su cultura. Por lo tanto, el contexto cultural en el que se desenvuelve la vida familiar de los indígenas se caracteriza por las particularidades y contextos en el que se desarrolla su modo de vida.

La organización y constitución de las comunidades Ch'oles están basadas en la familia Sandoval (1994:10), define a la familia como un sistema social delimitado por las redes de parentesco, la localización espacial y las actividades domésticas, fundada sobre la base del 
matrimonio en donde los hijos complementan la unidad familiar e integradas por una cultura que tiene como primordial consideración los lazos de parentesco que cimientan las relaciones sociales de los individuos. Como ya hemos visto, la familia de los Ch'oles de Tila constituye una unidad económica, política, social y religiosa; debido a que en ella se establece una relación más o menos sólida que obliga a cada uno de sus miembros a participar y cooperar en diversas actividades para garantizar su bienestar y supervivencia; es así, como a través de ella se finca una división social del trabajo en la que el padre, la madre y los hijos realizan labores especificas en estrecha cooperación. De igual manera, ésta determina cuáles son los derechos y obligaciones de cada uno de sus miembros, así como su participación ritual en ceremonias mágico-religiosas. ${ }^{19} \mathrm{La}$ participación económica de todos sus miembros es notoria, ya que los hijos desde muy temprana edad comienzan a colaborar en la economía familiar, de ahí es considerada como una unidad a la que contribuye cada miembro en la medida de sus posibilidades.

Es claro que el papel de cada sexo está fuertemente codificado; es así, que aunque los hombres y mujeres trabajen juntos en el campo y asistan a la misma escuela, en el hogar no realizan las mismas actividades; por lo que, un niño no debe realizar labores domésticas puesto que es una actividad propia de la mujer, sus obligaciones en el hogar están directamente relacionadas con el campo. Así explica Tyeko [LM.Chol.Of.MB.] que se lo enseñaron sus padres:

[...] En mi niñez mas que nada, este, en cuanto a barrer no me enseñaron [...] entonces, casi no nos permitían tocar lo que es la escoba y todo, entonces, "pa' que vas a barrer, allí tienes tu hermana que lo barra ", y en lo que sí nos exigían es ir a traer leña, recoger los cafés, cortar, todo [...]

El desempeño de un oficio (ya sea remunerado o no) de los padres o de la familia en su conjunto puede ser transmitido como herencia cultural del grupo al que se pertenece y para ello la familia estable una red de relaciones internas fuertemente codificadas en las que se promueven experiencias que garanticen el aprendizaje y realización de las actividades propias de los padres hacia los hijos. Ingresar al grupo de adultos y obtener el reconocimiento social de su grupo lo obtienen cuando ya son capaces de asumir responsabilidades mayores en el trabajo.

\footnotetext{
${ }^{19}$ Participan en celebraciones rituales de los santos, ya esa en danzas autóctonas, cargando a los santos en las peregrinaciones, ejerciendo funciones de mayordomos o pastores. También son quienes más arraigados tiene los cultos o rituales que se hacen a través de curanderos (oficio propio de los Ch'oles), en donde se invocan las fuerzas naturales (tierra, lluvia, etc.) y a Dios para obtener bienestar y salud.
} 
Se constata que la educación familiar y el aprendizaje que cada uno experimenta está íntimamente ligado al medio ambiente, a la comunidad y sobre todo a la diaria rutina de actividades que se desarrollan para contribuir al fortalecimiento y sobrevivencia de la unidad familiar. Los hijos de las familias Ch'oles de Tila aprenden a participar en la vida cultural, religiosa, económica, social y política, contribuyendo con su parte al bienestar familiar; ellos aprenden a cultivar cultivando, a cocinar cocinando, por lo que desde muy temprana edad mantienen relación directa con el medio en el que se desarrollará su vida adulta. En este sentido, puede decirse que prácticamente dejan de ser niños para pasar a ser pequeños adultos que realizan actividades encaminadas al sustento y sobrevivencia de la familia.

\section{Bibliografia}

AGNES Heller. Sociología de la vida cotidiana. Ed. Península; España, 1979.

ANDER-Egg, Ezequiel. La planificación educativa. Conceptos, métodos, estrategias y técnicas para educadores. Rio de la plata, 1993.

BAEZA Espejel, José Gabriel; GÓMES Guerreiro, María Gabriela; RAMÓN Silva, Noemí Elena. (Coord.). Pueblos indígenas: debates y perspectivas. UNAM. 2011.

BERGER P., y T. Luckmann. La construcción social de la realidad. Buenos Sires. Amorrortu, 1993.

CHANGE Norman. Antropología Cultural de Beals Alan. Ed. Pax-México, 1991.

CISNEROS, E. Formas de transmisión cultural entre los grupos indígenas mexicanos en: Cuadernos de la Cultura Pedagógica. UPN. México, 1990.

ESCALANTE y Miñano G. Investigación, organización y desarrollo de la comunidad. Oasis; México. 1982

el hombre y sus obras. FCE. México, 1981.

EZPELETA, Justa. Escuelas y maestros. Condiciones del trabajo docente en la Argentina. Buenos Aires, Centro Editor de América Latina, 1991.

GARCIA Castaño, F. Javier; GRANADOS Martínez, Antolín; PULIDO Moyano, Rafael A. Reflexiones en los diversos ámbitos de la construcción de la diferencia. En Lecturas para la Educación Intercultural. Trotta. Madrid, 1999. 
GIMÉNEZ, Gilberto. Comunidades primordiales y modernización en México, In: Gilberto Giménez y Ricardo Pozas H. (eds.), Modernización e identidades sociales, México D.F.: UNAM - Instituto de Investigaciones Sociales / Instituto Francés de América Latina (IFAL), 1994.

PÉREZ Chacón, José L. Los choles de Tila y su mundo, en Anuario Estadístico de Educación Indígena, Gobierno del Estado, Secretaría de Educación Pública (SEP), 1988.

SANDOVAL Forrero, Eduardo A. Familia Indígena y unidad domestica: llos otomíes del estado de México. UNAM, 1994.

Secretaria de Educación Pública. Subsecretaria de Planeación y Coordinación: Dirección General de Evaluación, 2001.

Seminario: Epistemologias y praxis cosmocentricas: el desafio de los conocimientos y prácticas indigenas. Desarrollado los días 14 y 15 de octubre de 2010. Universidad Pedagógica Nacional, Ajusco. México. Stefano Varece.

VALERA Barraza, Hilda. Cultura y resistencia cultural: una lectura política. SEP. 1985.

VARESE Stefano. Seminario: Epistemologias y praxis cosmocentricas: el desafio de los conocimientos y prácticas indigenas. Desarrollado los días 14 y 15 de octubre de 2010. Universidad Pedagógica Nacional, Ajusco. México. 2010.

ZERMEÑO, Sergio. La Sociedad derrotada. El desorden mexicano del fin de siglo. Siglo XXI editores. México. 2001.

ZIMMERMANN. K. Modos de Interculturalidad en la educación bilingüe. Reflexiones acerca del caso de Guatemala" Organización de Estados Iberoamericanos para la Educación, la Ciencia y la Cultura. Revista Iberoamericana de educación. Número 13. Educación Bilingüe Intercultural, OEA. 1997.

Submetido em 03 de abril de 2019.

Aceito em 09 de setembro de 2019. Publicado em 10 de setembro de 2019. 